\title{
An Enquiry into the Conceptual Identity of Wine Tourism - A Theoretical Synthesis
}

\author{
Anupama S Kotur*
}

\begin{abstract}
Many studies focussing on origin, growth and development of wine tourism in various parts of the world have shed light of facets that are unique to wine tourism. Through this research paper, the author aims to understand the variations presented in defining select terminologies in contemporary research in the domain, so as to be able to establish interlinkages with wine tourism. This theoretical synthesis is exploratory in nature and is based on review of extensive literature in the field of food tourism, culinary tourism, gastronomy tourism and wine tourism. The results of this study may be particularly useful to policy makers, industry practitioners of tourism promotion as well as academicians and researchers in the field of food and drink based tourism.
\end{abstract}

Keywords: Wine Tourism, Food Tourism, Culinary Tourism

\section{Introduction}

Wine tourism is essentially a synthesis of elements from wine and tourism industries that come together to form wine tourism experience. Wine tourism as an activity also integrates experiences

* Symbiosis Centre for Management Studies-Pune, Symbiosis

International (Deemed) University, Pune, India; anukotur@gmail.com 
that are food related such as food pairing and fine dining. Food has come to be generally accepted as an integral part of wine tourism experience. Wine tourism as a specific travel interest is a recent phenomenon. Wine tourism is considered to be a part of food and drink based tourism comprising of forms such as culinary tourism, gastronomic tourism and food tourism. Further, while discussing food and drink tourism many authors use the terms gastronomic tourism, culinary tourism or food tourism interchangeably. Some authors, however, are of the opinion that the use of the word 'gastronomy' implies the inclusion of 'fine dining' with a high level of culinary skill (Povey, 2011). Further, food based tourism is 'defined in (a) variety of ways depending on which aspect is focused on and what characteristics are more important to the development of the relationships between food and tourism' (Lin, 2006). Given the multidimensionality in the understanding of food and drink based tourism, the author was motivated to explore the similarities or dissimilarities between these terminologies and further understand the interlinkages that wine tourism has with them. The research paper presents a theoretical synthesis in order to enquire into the conceptual identity of wine tourism within the food and drink based tourism domain.

For the purpose of this qualitative enquiry, the study begins with overarching discussions on food, culinary and gastronomic forms of tourism. The discussion threads through conceptual underpinnings proposed by several studies in the area in order to build an argument about the interlinkages with tourism and further with wine tourism. At the heart of the research paper is the quest to study a wide range of variations within the understanding of food and drink tourism. The study relies on secondary data in the form of books and research articles in the domain.

\section{Literature Review}

\section{1 Food Tourism}

Destination experience is closely associated with food as it is an integral part of a place. Food centric experiences link visitors to a place. "Food has become a central part of the tourist experience, sparking an interest in promoting food as an enhancement of a 
particular destination or as the main attraction to a region" (Slocum\& Curtis, 2017). While eating is elemental in any holiday experience, Park, Kim \&Yeoman (2019) explain that when food "falls within the domain of tourism, food is no longer simply a matter of sustenance". One of the widely accepted definitions of food tourism was offered by Hall \& Mitchell (2001) who defined food tourism as "visitation to primary and secondary food producers, food festivals, restaurants and specific locations for which food tasting and/or experiencing the attributes of the specialist food production region are motivating factor for travel". Hall and Sharples (2003), however, opined that the "definition did not mean that any trip with visiting a restaurant or a food related location can be considered food tourism. A motivation with respect to experiencing food of a specific region held by tourists is the determinant factor" (Lin, 2006).

Yi-Chin Lin (2006), in the book Food Images in Destination Marketing, explained that "tourists travelling for all or nearly all food-related tourist activities are regarded as an example of gourmet and gastronomic tourism. The number of tourists with respect to gourmet and gastronomic tourism is relatively few compared to the other types of food tourism. The next type of food tourism is culinary tourism in which tourists show moderate interest in food. Finally, tourists with a subsidiary interest in food for travelling are regarded as the other type of food tourism, rural or urban tourism" (Hall \& Sharples, 2003). Hall \& Sharples (2003) and Trucer (2006) noted that food tourism is regarded as a form of special interest tourism (Lin, 2006).

In short, "food tourism should be understood from diverse viewpoints, because food serves multiple functions in tourism and is much more than biological needs in tourists' mind" (Fields, 2002, as cited in Hall \& Mitchell, 2003). In other words, food tourism is a comprehensive term that includes all travel where the primary attractions are the enjoyment of food and drink. These attractions may include visiting the points of food production, food shows, food festivals and speciality restaurants at the destination. Food tourism includes a whole range of interests and activities that revolve around the loci of food and drink at a destination with rich food culture. Within the tourism literature discussing food, 
numerous terms, namely 'food and wine tourism', 'tasting tourism', 'gourmet tourism', and most commonly 'culinary tourism', 'food tourism' or 'gastronomic tourism' are evident (Horng \& Tsai, 2012; Sanchez-Canizares \& Lopez Guzman, 2012 in Ellis, Park, Kim \& Yeoman, 2018). Presenting a futuristic view of food tourism Yeoman \&McMahon-Beatte (2018) argue that "food tourism is often portrayed as a visionary gaze due to images of local, regionality branded, authentic and the focus of economic development strategies in which tourists are climate aware and want a sustainable experience". According to Povey et al. (2011) food tourism is defined as "tourists visiting a destination specially to sample the food products offered there". Croce \& Perri (2010) opine that "food has become an object to analyse critically at tasting courses; it has become an object of art. In food and wine tourism, it is a transmitter of culture, an important economic factor and the embodiment of regional identity". Food tourism can, therefore, be recognised as a medium through which a destination conveys its geographical uniqueness, cultural identity, national pride and is a common thread that binds locals and visitors alike.

\subsection{Gastronomic Tourism}

Culinaria and gastronomy play a pivotal role in promoting a tourist destination (Dixit, 2019). Gastronomy in particular, amongst other cultural identities of a destination, plays an important role 'not only because food is central to the tourist experience, but also because gastronomy has become a significant source of identity formation in postmodern societies (Hjalager \& Richards, 2002). A simple explanation of gastronomy is enjoyment of food and beverage. It is also regarded as the art and/ or science of delicate eating. Regarding gastronomy tourism, it is "tourism or travel motivated, at least in part, by an interest in food and drink, eating and drinking"' (Santich, 2004, in Lin, 2006). Allen \& Alabala (2007)defined gastronomic tourism as 'trips made to destinations where the local food and beverages are the main motivating factors for travel'. Gastronomy is also' regarded as a symbol to express and enhance the identity which makes food a different motivation for tourists to travel' (Gyimothy \& Mykletun, 2008 in Guzel \& Apaydin, 2016). Many food tourism writers have opined that gastronomy tourism can be perceived as a subset of cultural 
tourism "because it is about participating in another culture associated with a particular place and people. A wide range of cuisine and agricultural tourism activities are then developed for tourists involving food and beverages. However, recently the focus of gastronomy tourism has shifted from consumption to production" (Santich, 2004, in Lin, 2006). In addition, it extends from farm visits and stays to museums and historical exhibitions. In view of this fact, gastronomy tourism goes far beyond mere dining experiences.

"Gastronomic tourism has been shown to be a valid segment to which destination can market, and it can conceivable (sic.) offer a valid tourism approach for areas not blessed with natural attractions" (Kivela \& Crotts, 2006, in Povey,2011). Quan and Wong (2004, in Povey, 2011) identified three benefits that gastronomic tourism present to the tourism destinations. Firstly, it

\begin{abstract}
"could be used by destinations to develop rural tourism and boost agricultural economy. Second, when destinations do have some gastronomic resources these can be easily used to develop trails, food festivals and a gastronomic tourism image. Third, foods can be included as a part of another attraction such as mega event and become a part of the tourism offer in this manner." (Quan \& Wong, 2004)
\end{abstract}

Gastronomic tourism is a great way to showcase the rich culinary tradition of the region by developing multitude food based experiences. Food based tourism can not only attract special interest tourists but also general interest tourists to a destination. "This has led to the emergence of local food and drinks festivals, as well as increased interest in local markets. Growth in this niche market is expected to be strong" (Allen \& Albala, 2007).

\title{
2.3 Culinary Tourism
}

Some studies opine that culinary tourism is synonymous with gastronomic tourism, while some others consider it as distinct from that of other forms of food tourism. One of the earliest understandings of this concept was given by Lucy Long in2004. According to Lucy Long (2004), culinary tourism is "the intentional, 
exploratory participation in the foodways of another - participation including the consumption, preparation, and presentation of a food item, cuisine, meal system, or eating style considered to belong to a culinary system of its own". The understanding of culinary tourism includes two elemental aspects.

"First, it is about tourists exploring food new to them and exploring the new culture associated with food. The second is that the hosts use food to sell their cultures and histories; they make food to marketable and attractive identities. It is because there are observable cultural differences in the way food is prepared, cooked, and preserved, and in the traditions of catering and eating food". (Hegarty \& O'Mahony, 2001)

Wolf (2006) describes culinary tourism as the 'combination of travelling, exploration, and enjoyment of food and drinks with unique and memorable gastronomic experiences (in Dixit, 2019). "Culinary tourism consists of travelling to experience culture through food and drink" (Boniface, 2003 as cited in Jolliffe, 2007). In short, culinary tourism may be understood as travelling to places to consume culinary experience typical to that region and learn about the culinary art and heritage that the place has to offer. Culinary tourism is where unique cuisine and food culture of the region form the primary attraction. Long (2013) introduced the concept of food ways where food represented "a network of activates and systems - physical, social, cultural, economic, spiritual, and aesthetic". Culinary interactions also allow tourists to "explore multidimetionality of the food systems" where they are able to gain insights on the "culture, region, time, ethos/religion, and socioeconomic class" of the place (Long, 2013).

Typically, culinary tours or food based tours are increasingly included as a part of other related activities such as rural home stays, culinary demonstrations \& workshops, farm walks, harvesting activities, and other cultural programmes. "There is an increased desire to sample local dishes, foodstuffs and drink" (Allen \& Albala, 2007) among the travellers which has come to become an elemental part of the entire holiday experience. On the other hand, for the culinary tourism organisers and enterprises, 
such tours come with many advantages as well. Lee Jolliffe, in his book 'Tea and Tourism: Tourists, Traditions and Transformations' (2007) observes some of the features of culinary tourism which have gone on to become the positive aspects of culinary tourism.

\begin{abstract}
"When we look closer to culinary tourism, we note the important aspects that make it worthwhile to deal with it, because compared to other forms of tourism, it is more versatile, which means among other things, that: $100 \%$ of the tourists must use the meals on the go. Is possible throughout the year, at any time of the day and regardless of the weather. Interest in cuisine in the journey, is not reserved for specific categories age, gender or nationality; Culinary art is the only area of art that speaks of all the five senses." (Jolliffe, 2007)
\end{abstract}

While, gastronomy "conveys the message of ethnicity, religion, status and identity through sensory experiences" (Civitello, 2008 in Dixit, 2019); culinaria in the context of gastronomy "describes country's or region's dishes, food and food preparation techniques which give rise to the country's or region's distinctive cuisine" (Kivela \& Crotts, 2008 in Dixit, 2019). While debate continues weather culinary tourism is synonymous with gastronomy tourism or do they have distinct definitions and identities, it would not be wrong to state that both these forms of tourism echo the idea that food opens up doors to cultural immersions a place has to offer.

\title{
2.4 Wine Tourism - an integral part of food and drink tourism
}

Wine Tourism is a niche form of food tourism that has, in recent years, caught the world travellers' attention. "...it was not until the early to mid-nineteenth century, with the invention of the restaurant and the commodification of cuisines into regional and national categories and as a result of the medium of cookbooks and codification of cooking styles, that food and wine became a travel product in its own right" (Novelli, 2007).

Wine tourism is travel to wine regions, vineyards, wineries, wine festivals to savour and learn about wines and in the process get an insight into the lives of farmers, wine makers, their culture. Some of the countries have perfected the art of wine making and have been 
promoting their land as a wine tourism destination for years. Italy, France, North America, Canada, Spain, Germany, Argentina, Portugal, South Africa, New Zealand and Australia are some the important wine countries that have drawn wine connoisseurs from around the world. While wine tourism is a niche segment of food tourism, it is by many authors considered a part of culinary and gastronomy tourism as well. Yuan et al. (2006) observed that "wine tourism is a newly emerged form of alternative tourism that overlaps both the wine and tourism industries.' It has been recognized as part of agricultural tourism, rural tourism, cultural tourism and special interest tourism as wine tourism shares close ties with tourism activities involved in these forms of tourism. "It is a form of Cultural tourism, niche tourism, a part of the gastronomic tourism" opine, Inacio \& Spinola (2010). Figure 1 below, illustrates interlinks between Food Tourism, Gastronomy tourism, Culinary tourism and Wine tourism.

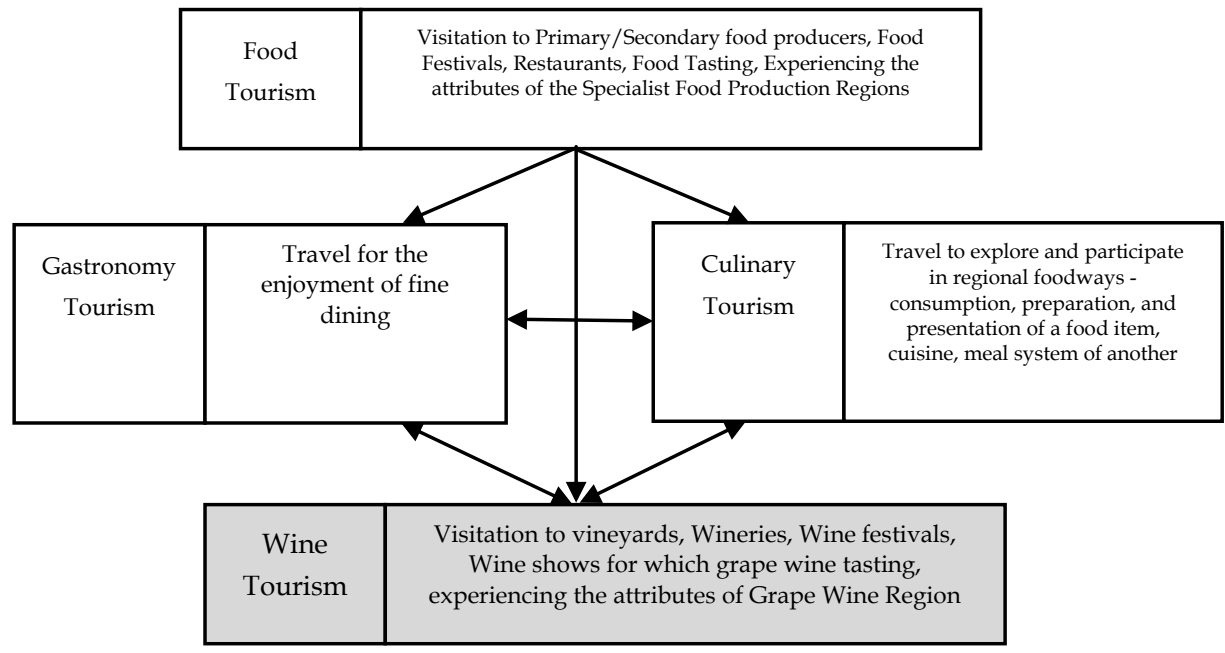

Fig 1: Interlink between Food Tourism, Gastronomy Tourism, Culinary Tourism and Wine Tourism

\subsection{Important highlights and conclusion}

Using the inductive reasoning, below are some of the emergent paradigms. 
a) Reflection Culture and Heritage

Both food and wine are akin in many dimensions. While foodways of a place reflect its culture and people, wine also is an integral part of culture.

b) Celebration and Enjoyment

Good food, traditionally, has been associated with celebration of social occasions and festivities. Enjoyment of fine food and wine is associated with good times. For instance, a good wine or champagne is usually stored away to celebrate a special occasion.

c) Enjoyment of Otherness

Travel, fundamentally, is enjoyment of 'otherness' that are unique to a place. It may be natural setting, culture, weather or food traditions. Enjoyment of cuisines unique a place is usually a part of most travel itineraries. Wine connoisseurs too travel to wine regions across the world to enjoy wines that are specific to that geography.

d) Linked to source of production

Wines globally identified by their region of their origin and so are cuisines and foodways.

Through this exploratory study, a number of observations emerged, a newer dimension of study was identified and newer research questions for future study emerged. Through the qualitative investigation process, a number of facets interlinking wine tourism with other forms for food based tourism were established. The results of this study may be particularly useful to policy makers, industry practitioners of tourism promotion as well as academicians and researchers in the field of food and drink based tourism.

\section{References}

Allen, G. J. \& Albala, K. (2007). The business of food: encyclopaedia of the food and drink industries. ABC-CLIO.

Croce, E. \& Perri, G. (2010). Food and wine tourism: integrating food, travel and territory. CABI.

Dixit, S. K. (2019). The Routledge handbook of gastronomic tourism. Routledge. 
Ellis, A. Park, E., Kim, S. \& Yeoman, I. (2018) What is food tourism. Tourism Management, 68, 250-263. Retrieved from https://doi.org/10.1016/j.tourman.2018.03.025 https:// www.tomorrowstourist.com/pdf/what_is_food_tourism.pdf;

Guzel, B \& Apaydin, M. (2016). Gastronomy tourism: motivations and destinations. global issues and trends in tourism. In C. Avcikurt, M. S. Dinu, N. Hacıoğlu, R. Efe, A. Soykan, N. Tetik (Eds), Global issues and trends in tourism, 394. St. Kliment Ohridski University Press.

Hall, C. M. \& Mitchell, R (2007). Gastronomic Tourism: Comparing wine and food tourism experiences. In M. Novelli (ed.), Niche tourism. Routledge.

Hall, C. M. \& Mitchell, R. (2001). Wine \& Food Tourism. In N.D.R Derrett (ed). Special interest tourism, Australia, John Wiley.

Hall, C. M., \& Sharples, L. (2003). The Consumption of experiences or the experience of consumption: An introduction to the tourism of taste. In C. M. Hall, L. Sharples, R. Mitchell, N. Macionis \& B. Cambourne (Eds.), Food tourism around the world: Development, management and markets (pp. 1-25). London: Butterworth-Heinemann.

Hall, C.M. \& Mitchell, R. (2003). Consuming tourists: food tourism consumer behaviour. In C.M. Hall, E. Sharples, R. Mitchell, B. Cambourne and N. Macionis (eds.), Food Tourism around the world: development, management and markets. Butterworth-Heinemann, Oxford, 60-80.

Hegarty, J. A., \& O'Mahony, G. B. (2001). Gastronomy: A phenomenon of cultural expressionism and an aesthetic for living. International Journal of Hospitality Management, 20, 3-13.

Hjalager, A.M., \& Richards, G. (2002). Tourism and gastronomy. London: Routledge.

Inacio, A. I. \& Spinola, S. C. (2010). Wine tourism and new media: a way to build identity and brand loyalty. Spring Symposium EUPRERA, Social Media Goes Mainstream: New challenges for internal communication, reputation, education and the public sector. Arteveldehoge school University College.

Jolliffe, L. (2007). Tea and tourism: tourists, traditions and transformations. Channel View Publications.

Lin, Y. C. (2006). Food images in destination marketing. ProQuest.

Long, L. M. (2013). Culinary Tourism (Google eBook).University Press of Kentucky.

Novelli, M. (2007). Niche Tourism. Routledge.

Park, E., Kim, S., \& Yeoman, I. (2019). Food tourism in Asia. Springer

Povey, G. (2011). Gastronomy and tourism. In P. Robinson, S. Heitmann, \& P.U.C. Dieke (eds.), Research themes for tourism. CABI. 
Povey, G. (2011). Gastronomy and tourism. In P. Robinson, S. Heitmann, \& P.U.C. Dieke (eds.), Research themes for tourism. CABI.

Slocum, S. L. \& Curtis, K. R. (2017). Food and agricultural tourism: theory and best practice. Routledge.

Yeoman, I. \& McMahon-Beatte, U. (2018). The future of food tourism. Journal of Tourism Futures, 2. Retrieved from https:// doi.org/ 10.1108/JTF-12-2015-0051

Yuan, J. J., Jang, S. S., Cai, L. A., Morrison, A. M. \& Linton, S. J. (2006). Analysis of motivational and promotional effects of wine festival. In Global wine tourism. In J. Carlsen (ed.), Research, management and marketing. CABI. 